\title{
An Exploration of Effective Evaluation Rubrics for Assessing the Writing Skill of Engineering Graduates
}

\author{
T.Anitha, K.Brindha
}

\begin{abstract}
The work breaks down the measurements pursued during the evaluation. The educators are liable for leading the appraisal. Consequently, the technique decides the different measures for examining composing strategies. A typical issue isn't finishing all parts of the assignment. Students should ensure they read the errand guidelines cautiously and find out precisely what they are required to do. The directions typically clarify that there are various explicit parts of the general assignment, all of which should be finished. To keep away from breakdowns in association and cognizance, it is prudent to compose a different section to manage every point. There ought to likewise be clear linkage between passages by alluding advances or in reverse in the content utilizing firm methods, for example, proper conjunctions, pronouns, redundancy or substitution of watchwords and expressions, and words, for example, 'this', 'that', 'already', 'next', and so on. Composing ought to be succinct and ought to exclude any superfluous or immaterial substance. Up-and-comers should ensure that they edit that they got done with composing cautiously to maintain a strategic distance from such syntactic blunders as poor sentence structure, off base subject action word understanding, conflicting or wrong utilization of particular and plural, poor word request, base tenses, erroneous utilization of grammatical forms (utilizing a modifier rather than an intensifier, or a thing rather than an action word, for instance) and inaccurate accentuation, just as spelling botches. Banalities, for example, 'enlarging their points of view's or 'accepting brilliant open doors' ought to be maintained a strategic distance from as they are now and again (mis)used and can prompt perplexity. Competitors are encouraged to invest more energy using English writings of the sort depicted in the Reading segment to build their jargon and to rehearse their composition. They ought to likewise be comfortable with the fundamental structure of a reasonable book. The review investigates the different measurements to be pursued when instructors right the test papers.
\end{abstract}

\section{INTRODUCTION}

Every homeroom should have a learned, capable teacher and instructive frameworks should enroll, prepare and hold instructors who can complete the duty. Anyway before long studies they generally make a horrible showcase of intentionally making and evaluating teachers.

Various course of action makers have starting late come to acknowledge that this mistake can benefit from outside intervention by finding out the improvement on stand-in marks on government-authorized exams in math as well as examining in a short time later depending strongly on these

Revised Manuscript Received on December 30, 2019.

T.ANITHA, Department of Science and Humanities, Sri Krishna College of Engineering and Technology, (An Autonomous Institution), Kuniamuthur, Coimbatore - 641008 , India.

DR.K.BRINDHA,Assistant Professor in English, Head, Department of English, Chikkanna Government Arts College, Tirupur - 641602, India.

\section{Keywords: Teachers, Students, Exam, Writing, Metrics}

checks to survey, reward and remove the instructors of these attempted stand-in's.

While there are substantial avocations for stress over the present plan of teacher evaluation, there are furthermore legitimate defenses to be stressed over cases that assessing instructors' practicality by large stand-in exam values leads to incite improved stand-in achievement. Besides of innovative rules else courses of action unequivocally require that teachers be ended in case their stand-in exam values doesn't rise through particular whole, by a much noteworthy graduates likely could be finished then this by and by the circumstance. In any situation isn't strong verification to show neither they was an weakest guider who going to leave, or that the pulling back guiders may superseded by dynamically convincing ones. Here the in like way adjacent to no evidence in the scenario that educators will be intelligently persuaded to improve stand-in grasping while guiders was assessed or monetarily made up for stand-in exam results gains.

An review of the specific evidence drives us to gather that, but state-endorsed exam results of stand-in was an information for college superiors to utilize for settle on choices about teacher ampleness, such results should be only a bit of a common sweeping evaluationone or two of states or at once considering plans that may provide the maximum amount as $1 / 2$ the load in pedagogue analysis and pay selections behalf of results on this preliminaries of basic aptitudes in scientific discipline and browsing.

A few techniques for assessment utilizing human decisions are habitually utilized. At times, the nature of framework yield is estimated straightforwardly, for example, with human decisions; in different cases, it is estimated by performing understanding tests or other downstream assignments, instill different cases it is estimated by computing the measure of work required to address the yield.

Two of the most widely recognized strategy human assessment measurements are familiarity and ampleness decisions. Familiarity requires a speaker conversant in the objective language to pass judgment on whether the framework yield is familiar, paying little heed to whether the substance of the yield is a precise interpretation of the source words.

Ampleness ignores the degree of familiarity with the framework yield and, to the extent; this is potential, measures whether the basic data in the source can be removed from the framework yield. The necessities for an

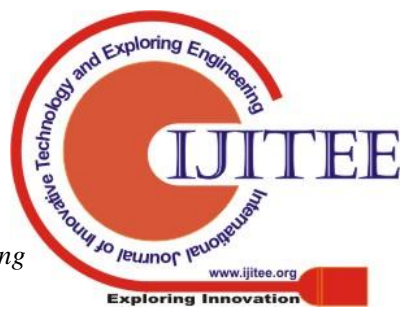


annotator of sufficiency are stricter than for familiarity, as the annotator must be bilingual in both the source and target language to pass judgment on whether the data is protected crosswise over interpretation. Practically speaking, an annotator familiar just in the objective language could likewise clarify sufficiency utilizing a lot of great human interpretations of the source sentence.

Familiarity and sufficiency are estimated independently on each sentence in the framework yield and are typically decided on a five or seven-point scale. They are some of the time arrived at the midpoint of to give a solitary numerical score to a framework yield. A few ponders have demonstrated the poor connection between's annotators utilizing this technique, bringing into question the unwavering quality of this strategy. By the by, human assessment has been utilized as a benchmark by which assessment measurements are much of the time judged. Decisions of semantic ampleness (and related thoughts, for example, understandability or familiarity) have kept on being utilized as incredibly helpful benchmarks for the presentation of measurements, although the unwavering quality of human decisions stays troublesome.

\section{IMPORTANCE OS ASSESSMENT}

A take a look at or appraisal (calmly, check or appraisal) is an evaluation supposed to measure exam-takers data, capacity, twisted, bodily wellbeing, or route of motion in a number of subjects. A exam may also be overseen verbally, on paper, online or in a destined locale that requires a exam taker to show or play out a ton of capacities. exams cross in style, painstaking first-rate and necessities. For example, in a shut e book exam, a check taker is in many instances required to depend on reminiscence to respond to unequivocal things while in an open e book exam, a exam taker may also use in any match one invaluable gadget, for instance, a reference book or smaller than traditional PC whilst responding. A take a look at may additionally be managed authoritatively or calmly. An occasion of an easygoing check is an examining take a look at limited through a guardian to an adolescent. A appropriate exam might be the closing appraisal oversaw by a trainer in a homeroom or an I.Q. take a look at coordinated by an investigator in an office. Formal checking out automatically realizes an evaluation or a exam score. A exam rating may also be deciphered regarding a widespread or rule, or now and again both. The trendy may be developed selfsufficiently, or by way of genuine assessment of a terrific number of individuals. A take a look at is predicted to exam a bit of individuals' data or capability for providing he period to manage that subject.

A state-authorized exam might be any exam which was administrated and evaluated normally to ensure genuine faultlessness. State administered tests are every now and again used in guidance, capable accreditation, cerebrum science and various fields.

Non-state embraced exam is normally adaptable in degree and approach, variable in a predicament and significance. Hence this exams are generally made by lone teachers, the arrangement and issue of these exams might can't be thoroughly gotten a handle on or utilized by different instructors or establishments. A non-state oversaw exam might be utilized to pick the capacity level of stand-ins, to persuade stand-ins to consider and to offer commitment to stand-ins. In explicit models, an instructor may make nongovernment approved exams that take after statecoordinated exams in development, game plan and issue to set up their stand-ins for a bleeding edge state-directed exam. At long last, the rehash and setting by which a nonstate approved exams are composed are uncommonly factor and are normally obliged by the scope of the class time assignment. A class instructor may, for instance, direct a exam on seven days by week premise or just twice a semester. Subordinate based on approach by teacher alias foundation, the length of each exam is prop up for just five minutes to a whole period of class.

In contrasts to non-state authorized exams, authorizedendorsed exams was comprehensively used, fixed with respect to expansion, issue, and structure which are typically basic in results. State-authorized exams was ordinarily conduct tight allocated timing as directed by exam engineer, enlightening association, regulating members might be coordinated through superior and placed inside investigation corridor, else constrained through homeroom time allotment. Despite the fact that may be a small vacillation within various copies of a comparative kind of StateEndorsed Test (e.g., SAT) based on various authorization exam there will be variabilities.

Each exam with major consequences for the individual exam takers implied as a high-risk exam. A exam can be made and watched by an instructor, a doctor, directing agency, or provider of exam. In certain events, which fashioner exams may not be totally responsible for the relationship. For example, the Educational Testing Service (ETS), a examing and assessment brighten altruistic affiliates, make a exam of the authorities, for example, SAT, however, may not actually locked by the association or the pointing of this exam. Likewise, the same as with the development and associated informative exam, a game plan and issue rate of self exams and no significant factors or wide agreement consistent standard exam settings and problems. Consistently, the association and the issue of poor exam perspective on information from the instructor, subject, class size, the basic approach of education and the importance of accreditation or manage weight. At the point when all is said done, examing conducted and coordinated by specialized instructors are non-systematic but exams performed by affiliates standardized exam.

\section{PRACTICES FOLLOWED IN GRADING THE EXAMS}

The most evident capacity of appraisal techniques, (for example, tests, papers, and introductions) is to empower teachers to make decisions about the nature of understudy learning (i.e., dole out evaluations). In any case, the strategy for appraisal likewise can directly affect the nature of understudy learning. Understudies expect that the focal point of tests and assignments mirrors the instructive objectives generally esteemed by an educator, and they 
direct their learning and examining in like manner. General reviewing frameworks can affect too. For instance, an exacting chime bend (i.e., standard reference evaluating) can hose inspiration and collaboration in a homeroom, while a framework that carefully compensates capability (i.e., model referenced reviewing) could be seen as adding to review swelling. Given the significance of appraisal for both personnel and understudy associations about realizing, in what capacity would instructors be able to create tests that give valuable and pertinent information about their understudies' learning and furthermore direct understudies to invest their energy in the significant parts of a course or course unit? How do evaluating rehearses further impact this procedure?

Table No: 1 Question Types

\begin{tabular}{|c|c|c|}
\hline Question Type & Advantages & Disadvantages \\
\hline True-F alse & $\begin{array}{l}\text { Many items can be administered } \\
\text { in a relatively short time. } \\
\text { Moderately easy to write; easily } \\
\text { scored. }\end{array}$ & $\begin{array}{l}\text { Limited primarily to testing } \\
\text { knowledge of information. Easy } \\
\text { to guess correctly on many items, } \\
\text { even if material has not been } \\
\text { mastered. }\end{array}$ \\
\hline Multiple-Choice & $\begin{array}{l}\text { Can be used to as sess broad } \\
\text { range of content in a brief period. } \\
\text { Skillfully written items can } \\
\text { measure higher order cognitive } \\
\text { skills. Can be scored quickly. }\end{array}$ & $\begin{array}{l}\text { Difficult and time consuming to } \\
\text { write good items. Possible to } \\
\text { assess higher order cognitive } \\
\text { skills, but most items assess only } \\
\text { knowledge Some correct } \\
\text { answers can be guesses. }\end{array}$ \\
\hline Matching & $\begin{array}{l}\text { Items can be written quickly. A } \\
\text { broad range of content can be } \\
\text { assessed. Scoring can be done } \\
\text { efficiently. }\end{array}$ & $\begin{array}{l}\text { Higher order cognitive skills are } \\
\text { difficult to assess. }\end{array}$ \\
\hline Short Answer or Completion & $\begin{array}{l}\text { Many can be administered in a } \\
\text { brief amount of time. Relatively } \\
\text { efficient to score. Moderately } \\
\text { easy to write. }\end{array}$ & $\begin{array}{l}\text { Difficult to identify defensible } \\
\text { criteria for correct answers. } \\
\text { Limited to questions that can be } \\
\text { answered or completed in very } \\
\text { few words. }\end{array}$ \\
\hline Essay & $\begin{array}{l}\text { Can be used to measure higher } \\
\text { order cognitive skills. Relatively } \\
\text { easy to write questions. Difficult } \\
\text { for respondent to get correct } \\
\text { answer by guessing. }\end{array}$ & $\begin{array}{l}\text { Time consuming to administer } \\
\text { and score. Difficult to identify } \\
\text { reliable criteria for scoring. Only } \\
\text { a limited range of content can be } \\
\text { sampled during any one testing } \\
\text { period. }\end{array}$ \\
\hline
\end{tabular}

In a perfect world, successful tests have four qualities. They are:

- Valid, (giving helpful data about the ideas they were intended to test),

- Reliable (permitting predictable estimation and segregating between various levels of execution),

- $\quad$ Recognizable (guidance has arranged understudies for the appraisal), and

- Realistic (concerning time and exertion required to finish the task)

The sort of things and the favorable circumstances and burdens of the different inquiries are given in table 1 .

\section{RUBRICS FOLLOWED BY TEACHERS WHILE CORRECTING THE ENGLISH EXAM PAPERS\& RESULTS}

\subsection{Tenses}

Tense, the verb modifiers and connecting glimpse provide information about when the events portrayed in English sentences occur. To isolate this interim information of the sentence, to be decomposed into a depiction of semantic gaining significance tense, common modifiers and brief liaison. Depiction submitted for basic tenses, some modifiers said provisional measures, as a part of public liaison. Five criteria are prescribed for choosing this portrayal and depiction judged subject to this criteria.

The sentences of english holds numerous kinds of fleeting data. Tense is utilized to illuminate the peruser (audience) during occasion related to principle action word happens concerning the hour of expression. That is, tense advises the peruser that an occasion happens previously, after, or during the hour of articulation. Fleeting verb modifiers, (for example, tomorrow or now) include extra data about the occasions in a sentence. Fleeting connectives enlighten the peruser regarding the transient connection inside occasions on primary proviso as well as occasions on subordinate condition. Since the otherworldly data which might caught in phrases, the accompanying must focus on that things. To extricate transient data in a phrase, which will be parsed with meaningful portrayal that catches the valuable in tense, worldly verb modifiers and fleeting connectives. A fleeting portrayal of tense, verb modifiers and worldly connectives must:

1. Give an approach to dismiss transiently off base sentences, for example, * "I will run tomorrow."

2. Enable one to reason about the transient connection between occasions. For example, the sentence "I had run when he showed up" infers that the run occasion happens before the appearance, while in the sentence "I was running when he showed up," the appearance and run occasions cover.

3. Enable the specific time of occasion to be unfixed until it is pinpointed dependent on relevant data or word intensifying alteration.

4. Enable reference to focuses and interims of time (eg. accurately at 3 PM VS. for 5 hours).

5. Permit parsing of worldly data in sentences to be basic and compositional.

The portrayals for tense, verb modifiers, and worldly connectives created here depend on McDermott's (1982) transient rationale. McDermott's "point-based" worldly rationale was picked because it isn't unordinary to discuss the start and end purposes of a timeframe or an occasion. Here, the semantics of tense created here relate the endpoints of occasions in sentences. This portrayal of tense gives adaptability not found in numerous different portrayals of tense. Adaptability is significant since occasions can reach out over tense limits (for example, "in a short time, the kid will have run for 24 hours."). Any portrayal of occasions in time should catch the way that a few occasions don't in every case entirely happen before, present, or future as for the hour of expression.

The strained guidelines are compositional and require the accompanying relations : < (previously), > (after), = (cotemporaneous), < (previously or contemporaneous), and $>$ (after or contemporaneous). It is accepted that occasions are "unit" occasions and have a start and an endpoint, where

Published By: 
the start of an occasion is previously or concurrent to its endpoint. The endpoint of an occasion need not infer the accomplishment of the reason with which the occasion was started (e.g. the presence of the end purpose of a triumphant occasion need not suggest that the condition of having won is accomplished). To catch the importance of straightforward just as increasingly complex tenses, we present the accompanying occasions:

1. Articulation Event - This is essentially the talking occasion related to a sentence.

2. Headliner - This is the occasion shown by the principle action word of the sentence. For example, the run occasion in the accompanying sentence is the headliner: "I have been racing to the store."

3. Immaculate Event - This is the time interim alluded to in sentences like: "Bill had eaten at 3 PM," which depicts an eat occasion in the "removed past." This sentence infers the presence of an occasion or time interim which happens after the headliner (eat) yet before the articulation occasion.

4. Dynamic Event - This is the time interim from which the headliner stretches out into the past and into what's to come. The dynamic occasion may have no relationship with a "genuine world" occasion; however, its reality predicts certain marvels in our model of fleeting verb modifiers and connectives. It tends to be thought of as a spot holder, or the negligible conceivable term of a headliner with a dynamic viewpoint. The accompanying five guidelines depict the semantics of tense both in English and in our portrayal. The action words in a sentence are parsed left to right (accepting an ATN, which is the parser wherein these strained standards were actualized). One of the accompanying three principles is activated by the strained of the primary action word in the sentence. "Occasion" (in the quick three guidelines) can be a headliner, an ideal occasion, or a dynamic occasion contingent upon the sentence.

1. Past rule: This standard infers that there exists some occasion that must end before the start of the expression occasion. (< (end occasion (start expression occasion)

2. Present rule: This standard infers that there exists some occasion that is either contemporaneous with the expression occasion or can start at or after the start of the articulation occasion. Which is stated appears to rely upon the part of the action word related to the occasion. On the off chance that the present action word is stative, at that point (and (= (start occasion) (start articulation occasion)) (= (end occasion) (end utterance-occasion))) If the present action word is anything but a stative at that point ('d (start occasion) (start expression occasion))

3. Future rule: This standard suggests that there exists some occasion that must start after the finish of the articulation occasion. (> (start occasion) (end articulation occasion)) The accompanying principles are required to translate the more entangled immaculate and dynamic tenses.

4. Impeccable rule: This standard is activated by the word have pursued by a past participle. The occasion in the standard can be a dynamic or a headliner. $(<$ (end occasion) (start impeccable occasion))

5. Dynamic rule: This standard is activated by the word be trailed by a dynamic action word structure. The occasion in the standard must be a headliner. (furthermore, $(<$ (start headliner) (start dynamic occasion)) (end headliner) (end dynamic occasion)))

\subsection{Spelling Mistakes}

Spelling blunders were recognized in the examined composition by two analysts, works first independently, and then as a group. Every scientist previously experienced the printed forms of the content examples distinguishing and checking spelling blunders. The two arrangements of mistakes and checks were then thought about, again grade by grade, and any errors distinguished and talked about. At any stage, it was additionally conceivable to assess the transcribed contents to check precisely what the competitor had composed. The opportunity to be vindicated was given regardless where there was vagueness, which generally emerged as an outcome of either poor penmanship, or poor separating method. Sometimes it was important to look somewhere else in the up-and-comer's content for instances of specific letters or letter mixes or to take a gander at the separating between different words to see whether the nearness or nonattendance of dispersing gave off an impression of being conscious for the up-and-comer.

\subsection{Temporal Connectives}

Several problems want to be analyzed in starting process of the portrayal of fleeting connectives. Initially ought to be called attention to that fleeting connectives are lower. Most low ranking don't confine the strained of the inferior statement given the strained of the principle condition. The strained of the primary provision restricts the strained of the subordinate statement when the lower ranking is a transient connective. The accompanying outcomes are anticipated by Hornstein (1977):
John left when Harry
1. *arrives.
4. anrived
7. *will come
2. *is arriving
5. was arriving
8. *will be coming.
3. *has arrived.
6. had come
9. *will have arrived.

By contemplating the above model, one may recommend that the strained of the primary proviso and the strained of the subordinate statement must have a similar sense (ignoring dynamic and immaculate angles). This is by all accounts valid for all over a wide period tenses. There are a few confinements of this announcement, be that as it may, since the will/shall the development of future tense isn't permitted in fleeting subordinate provisions. As pointed out in (1971):

On the off chance that the will/shall development is utilized in a subordinate statement presented by a transient connective, at that point the perusing of the sentence is certifiably not a future yet modular. This reality was not seen by Hornstein $(1977,1981)$ or Yip (1985). Hornstein permits both current state and will/shall future tense to 
happen in fleeting subordinate provisos. Howl just permits the will/shall future tense to happen in the subordinate condition.

As opposed to remembering the syntactic needs of transient connectives for our semantic portrayal, it appears to be savvier to incorporate the necessity at a syntactic level. That is strained of the first action word of the fundamental statement that limits the strained of the main action word in the fleeting subordinate proviso. On the off chance that the strained of the principal action word in the primary condition of the sentence is past or present, at that point the strained of the main action word in the subordinate provision must have like tense. On the off chance that the strained of the principal action word in the principle statement is future tense, at that point, the strained of the main action word in the subordinate provision must be the current state (however it will be semantically interpreted as future tense).

Presently, we should think about how to remove the fleeting importance of sentences of the structure sentenceworldly connective-sentence. Every statement will be given a transient portrayal as showed in the strained portrayal, area of this work. The two statements will have a similar time of articulation since an expression occasion is made uniquely for a sentence. The main nuance is the prerequisite that the current state in a subordinate provision be interpreted utilizing future semantics when the fundamental proviso has a future tense. After every statement is spoken to, the semantics for the fleeting connective must be conjured. Every transient connective requires its definition, as pointed out by Hornstein(1977). These definitions will decide the fleeting connection between the occasions in the primary condition and the occasions in the subordinate proviso. We will display the definitions for five worldly connectives: when, while, until, previously, and after. Since these definitions can utilize the portrayal of tense related to every condition in a sentence to interrelate the occasions between statements, the quality of the strained portrayal is expanded.

When: adjust the stay occasions to decide the connection between occasions of the conditions. If the headliners of the two conditions are the stay occasions, at that point, the occasions may happen at the very same time, however not really.

While: adjust the grapple and headliners of the conditions. Verify whether the arrangement of both is conceivable. If checks. - enums, at that point, dismiss the sentence.

Until: requires much of the time that the headliner of the fundamental condition ends when the headliner of the subordinate proviso starts. On the off chance that the strained portrayal of the subordinate proviso has an ideal occasion and no dynamic occasion, at that point, the headliner of the principle condition must end when the headliner of the subordinate statement closes.

Before: necessitates that the stay occasion of the fundamental condition end before the start of the headliner of the subordinate proviso.

After: requires much of the time that the headliner of the principle statement starts after the finish of the stay occasion of the subordinate condition. On the off chance that the principal provision has a dynamic occasion, at that point, the grapple occasion of the primary statement starts after the finish of the stay occasion of the subordinate proviso and the headliner of the subordinate condition finishes before the finish of the headliner of the fundamental condition.

\subsection{Coherence}

Discernment is practiced when sentences and thoughts are related and stream together effectively. An article without objectivity can control a per user's ability to appreciate the thoughts and essential worries of the paper. Knowledge empowers the per user to move viably all through the article beginning with one idea then onto the following, beginning with one sentence then onto the following, and beginning with one section then onto the following. Following are a couple of procedures that can be used to achieve objectivity recorded as a printed version:

Use Repetition to Link Ideas, Sentences, and Paragraphs Repeating catchphrases or expressions interfaces and center idea(s) all through the exposition. Redundancy likewise enables the peruser to stay engaged and headed the correct way.

Utilize Transitional Expressions to Link Ideas, Sentences, and Paragraphs - Transitional articulations, for example, in any case, because, in this manner, and moreover, are utilized to set up connections between thoughts, sentences, and passages. They fill in assign to tell the peruser the past thought, sentence, or passage is associated with what pursues. For a rundown of the most ordinarily utilized transitional articulations, elude toward the Southeastern Writing Center's freebee Useful Transitional Words and Phrases.

Use Pronouns to Link Sentences - Pronouns are utilized to interface or associate sentences by alluding to going before things and pronouns. Pronouns can likewise help make sections that are anything but difficult to peruse by dispensing with tedium and superfluous reiteration.

Use Synonyms to Link Ideas and Create Variety Synonyms are words that have the equivalent of almost a similar importance as other words. They give elective word decisions that can change up a paper and can help take out superfluous reiteration.

Utilize Parallel Structures to Link Ideas, Sentences, and Paragraphs - Parallelism is the utilization of coordinating words, expressions, provisos, or sentence structures to express comparable thoughts. Parallel structures enable the peruser to stream easily from one thought, sentence, or passage to the following and to comprehend the connections and associations between thoughts.

\subsection{Grammatical and Lexical Cohesion}

The idea of union can't be isolated from the idea of 'content'. Content can be spoken or composed that forms a brought together entirety. What varies content and noncontent lies on the 'surface', and this surface is built by the firm relations between its linguistic highlights. Further, Beaugrand and Dressler1 (1981) characterize content as an informative occurrence, which fulfills seven guidelines of textuality: 
- 'Attachment' that alludes to the surface content; for example, linguistic conditions in the surface content.

- 'soundness' alluding to the literary world, for example, the design of ideas and relations which underlie the surface content

- 'deliberateness' alluding to the content author's frame of mind.

- 'worthiness' alluding to the content peruser's disposition to the content

- 'informativity' alluding to the degree to which the message of the content is (un) expected, (un)known, and so on

- 'situationality' alluding to the variables that make a book important to a circumstance

- "intertextuality' alluding to the variables which make the use of one content endless supply of recently experienced writings

Attachment is in the degree of semantic, which alludes to relations of implying that exist inside the content, and that characterize it as a book (Ruqaiya and Hasan2, 1976). Attachment happens when the understanding of some components in the talk is reliant on that of another. Syntactic attachment is built by the linguistic structures every segment ties one another.

\section{CONCLUSION}

This work portrays a starter investigation of the worldly marvels found in English sentences for English tests by educators. Different issues have been expelled for straightforwardness. For example, the issue of reliable readings of action words was not analyzed. The repercussions of action words with transient points of view, (for example, plan) were additionally not considered. The central occasions from various sentences that can be related are the explanation occasions. If two sentences happen in movement, one can wrap up just that the articulation occasion of the essential finishes before the enunciation occasion of the second. The model made here can, notwithstanding, quickly request occasions inside a sentence. Five criteria were proposed near the start of the paper for the portrayal of transient data found in an English sentence. These criteria guided the progress of our model. All criteria were met, beside the compositional parse foundation in a couple of cases. There give off an impression of being unavoidable remarkable cases that can't be trapped in the compositional tenses, qualifier, and fleeting connective guidelines. For instance, the ramifications of certain action word modifiers require tense information to choose their correct depictions. Hence the above mentioned methods can be employed for effective English exam paper correction by teachers.

\section{REFERENCES}

1. Allen, James. Maintaining Knowledge About Temporal Intervals. CACM, 1983, 26, 832-843.

2. Leech, Geoffrey N. Meaning and the English Verb. London : Longman, 1971.

3. McDermott, Drew. A Temporal Logic For Reasoning About Processes And Plans. Cognitive Science, 1982, 6, 101-155.
4. Reichenbach, Hans. Elements of Symbolic Logic, New York : MacMillan, 1947.

5. Yip, Kenneth M. Tense, Aspect and the Cognitive Representation of Time. IJCAI Proceedings, 1985, 806814 